\title{
Triagem psicológica: da escuta das expectativas à formulação do desejo
}

\author{
Rita Aparecida Nicioli Cerioni' \\ Universidade de São Paulo, SP, Brasil \\ Eliana Herzberg \\ Universidade de São Paulo, SP, Brasil
}

\begin{abstract}
Resumo: A pesquisa visa analisar as expectativas acerca do atendimento psicológico verbalizadas no processo de triagem por pacientes de um Serviço-Escola e relacioná-las a desejos inconscientes. Foi utilizado o método clínico-qualitativo e apresentado um caso atendido na triagem. $O$ atendimento foi individual, com 2 sessões de 60 minutos, utilizando-se entrevista semiestruturada. Foram abordadas as queixas, histórias clínica e de vida, fantasias acerca do atendimento psicológico e expectativas. A análise foi baseada na teoria psicanalítica de Freud. Conclui-se que, ao investigar as expectativas em relação ao que se espera dos atendimentos, torna-se possível, ao menos em alguma medida, acessar o desejo inconsciente, abrindo caminho para compreensão de sua dinâmica.
\end{abstract}

Palavras-chave: triagem psicológica; escuta psicanalítica; desejo inconsciente; psicanálise clínica; expectativas.

\section{PSYCHOLOGICAL SCREENING: FROM LISTENING TO EXPECTATIONS TO FORMULATIONS OF DESIRE}

\begin{abstract}
The research aims to analyze verbalized expectations of the psychological care in the screening process for patients of a Psychological Clinic of a University, and relate them to the unconscious desires. The clinical-qualitative method was applied to a case addressed in the screening process. The service provided consisted in 2 sessions of 60 minutes, using a semi-structured interview. Complaints, clinical and life stories, fantasies around the realm of the psychological care and expectations were also regarded. The analysis was based on psychoanalytic theory of Freud. It was concluded that investigating expectations about what is hoped from the psychological care, makes it is possible, at least to some extent, to access the unconscious desire and to understand its dynamics.
\end{abstract}

Keywords: psychological screening; psychoanalytic listening; unconscious desire; clinical psychoanalysis; expectations.

\section{EVALUACIÓN PSICOLÓGICA: DE LA ESCUCHA DE LAS EXPECTATIVAS HASTA EL DESEO}

Resumen: El estudio tiene por objeto analizar las expectativas sobre la atención psicológica expresadas verbalmente por pacientes de un Servicio Escuela en el proceso de evaluación y relacionadas con los deseos inconscientes. Se usó el método clínico cualitativo e se presentó un caso atendido en la evaluación. La atención fue individual, con 2

${ }^{1}$ Endereço para correspondência: Rita Aparecida Nicioli Cerioni, Universidade de São Paulo, Rua Rangel Pestana, 828, sala 37, Centro - Jundiaí - SP - Brasil. CEP: 13201-000. E-mail: ritacerioni@usp.br. 
sesiones de 60 minutos, utilizando una entrevista semiestructurada. Se abordaron las quejas, las historias clínicas y de vida, las fantasías sobre la atención psicológica y las expectativas. El análisis se basó en la teoría psicoanalítica de Freud. Se llegó a la conclusión de que al investigar las expectativas con relación a lo que se espera en la atención, se hace posible, al menos de alguna forma, tener acceso al deseo inconsciente, abriendo camino a la comprensión de su dinámica.

Palabras clave: evaluación psicológica; escucha psicoanalítica; deseo inconsciente; psicoanálisis clínico; expectativas.

De acordo com a definição tradicional, a triagem psicológica tem os objetivos de coletar dados, levantar hipóteses diagnósticas e verificar qual tipo de atendimento a pessoa necessita, a fim de encaminhá-la ao tratamento adequado possível (Herzberg \& Chammas, 2009). Outros estudos propõem a triagem interventiva, ampliando a ideia de triagem tradicional (Perfeito \& Mello, 2004; Herzberg \& Chammas, 2009). A triagem interventiva envolve um processo dinâmico, um encontro entre duas pessoas com papéis distintos e integrados. Neste modo de intervenção:

O encontro entre terapeuta e cliente é muito valorizado e o foco principal passa a ser o acolhimento das pessoas e a elaboração das questões que mobilizaram a busca de ajuda psicológica. O profissional, nessa perspectiva, não realiza uma sessão devolutiva como acontece nas triagens tradicionais, mas comunica sua compreensão, compartilha suas impressões a partir do que está ouvindo e vendo (Rocha, 2011, p. 127).

Um estudo sobre a escuta das expectativas de pacientes acerca do atendimento psicológico no processo de triagem aponta que, ao procurar esse serviço, os pacientes chegam com fantasias, esperanças, medos e desejos (Cerioni, 2014). Escutar em psicanálise é escutar o desejo: "A situação analítica é, por excelência, uma situação de comunicação: nela circulam demandas, nem sempre lógicas ou de fácil deciframento, mas as quais, em seu cerne, comunicam o desejo e a necessidade de serem escutadas" (Macedo \& Falcão, 2005, p. 65). Escutar as expectativas parece articular-se com a escuta do que o sujeito deseja e a forma como ele articula esse desejo e suas representações.

No entanto, segundo Alves (2004), parafraseando Alberto Caeiro: "Não é bastante ter ouvidos para se ouvir o que é dito. É preciso também que haja silêncio dentro da alma" (Alves, 2004, p. 67). Freud só chegou à técnica da associação livre ao silenciar.

Ouvir, para Freud, tornou-se mais do que uma arte; tornou-se um método, uma via privilegiada para o conhecimento, à qual os pacientes Ihe davam acesso. Um dos guias a quem Freud sempre foi grato era Emmy Von N. que Freud atendeu em 1889 e 1990 e tratou com a técnica hipno-analítica de Breuer ... ela proporcionou uma veemente lição prática ao seu médico. Quando Freud a interrogava com insistência, ela se aborrecia "muito rispidamente", e pedia que ele parasse de "Ihe perguntar de onde veio isso ou aquilo, mas que a deixasse contar o que ela tinha a dizer". Ele já havia reconhecido que, por mais tediosas e repetitivas que fossem suas narrativas, ele não ganhava nada com suas interrupções, mas que tinha que ouvir as histórias dela até o fim, com todos os seus minuciosos detalhes (Gay, 2004, pp. 80-81). 
Entende-se que há uma diferença importante entre ouvir e escutar. De acordo com Macedo e Carrasco (2005), essa diferença, embora amplamente difundida em psicanálise, transcende uma teoria. Enquanto ouvir é uma condição fisiológica ligada aos órgãos sensoriais, escutar diz respeito a uma disponibilidade integral e não só sensorial àquele que fala de sua dor, dor que traz consigo um significado próprio e singular: "A verdadeira escuta precisa estar desprovida de preconceitos e, principalmente, excluir qualquer possibilidade de um pré-conhecimento a respeito daquele que chega e, agora, fala" (Macedo \& Carrasco, 2005, p. 29). Um debruçar-se sem saber a priori, sentido essencial da escuta clínica. A escuta clínica psicanalítica é uma escuta do sofrimento, do padecimento do sujeito e, por ser clínica é uma escuta das dimensões inconscientes das experiências do sofrimento. A escuta não só é condição para o que se faz em psicanálise, como muitas vezes é disso que o sujeito necessita em primeira instância: uma escuta sensível e diferenciada, sem a qual nada pode ser feito.

No estudo sobre triagem estendida (Herzberg \& Chammas, 2009), são apontadas algumas expectativas dos pacientes em relação ao atendimento psicológico, tanto positivas, como uma alta expectativa em receber ajuda, quanto negativas, como receber um rótulo-diagnóstico, dúvidas quanto a receber ajuda de psicóloga jovem ou mulher. De qualquer forma, a escuta da expectativa leva o psicólogo a uma escuta do seu desejo, ainda que parcialmente e, portanto, de seu funcionamento.

Assim, ao escutar as expectativas escuta-se, também, o desejo, pois as expectativas do paciente revelam como aquele sujeito se articula com o desejo e com o sofrimento, portanto escutá-las significa também escutar e compreender parcialmente essa articulação; é uma porta de entrada. Mas, prioritariamente, escutar as expectativas é dar voz e legitimar o desejo e, só a partir daí, poder esclarecer e ajudar o paciente a entrar em contato com uma parte de si muitas vezes desconhecida. Isso, por si só, já caracteriza uma intervenção psicológica.

Expectativas e desejos são experimentados pelo sujeito a partir da sua própria subjetividade e esta se relaciona com a história afetiva de cada um. Supostos direitos, possibilidades, pressupostos, promessas e esperanças passam pela interpretação que cada pessoa tem de si, do mundo e do outro. Não é simples pensar em expectativa, pois esta articulação com a vida pessoal a torna complexa.

Ao construir um enunciado acerca das expectativas, o paciente o remete a um destinatário: aquele que escuta, e que está colocado na cena transferencial. É na transferência, nesta reedição de protótipos infantis de relacionamento, que aspectos primitivos são comunicados (Freud, 2006b).

Na clínica da atualidade há uma questão cada vez mais comum, indagação pré-edípica: "Quem sou eu?". Se antes o sofrimento estava no campo da competição edípica, hoje as questões que aparecem na clínica são falhas na constituição do eu, trazendo um horror diante do não saber de si, revelando o desamparo de quem olha e não sabe o que enxerga (Gobbi, 2008). Indagação que aponta para uma reedição do narcisismo postulado por Freud (2006d), no texto "Sobre o narcisismo: uma Introdução". 
Em relação ao conceito de desejo, toma-se a definição de Freud (2006a), no livro "Interpretação dos sonhos", que descreve a partir da concepção dinâmica como um dos polos do conflito defensivo. Difere-se da necessidade, pois esta estaria ligada mais às demandas fisiológicas, como fome ou sono, por exemplo. $\mathrm{O}$ desejo em Freud está relacionado às vivências primordiais de satisfação. Teria um apoio biológico, mas encontraria na alucinação dessa satisfação, o nascimento do desejo.

Suposições que hão de fundamentar-se num outro momento nos dizem que o aparato psíquico obedeceu primeiramente ao afã de manter-se o mais possível isento de estímulos... Porém, a estimulação da vida externa perturba esta simples função; a ela deve o aparato também o empurrão para sua constituição ulterior. A estimulação da vida o assedia primeiro na forma das grandes necessidades corporais. A excitação imposta pela necessidade interior buscará uma drenagem na motilidade que pode designar-se "alteração interna" ou "expressão emocional". [Tal situação] só pode modificar-se quando por algum caminho (no caso da criança, pelo cuidado alheio), se dá a experiência da vivência de satisfação que cancela o estímulo interno. Um componente essencial desta vivência é a aparição de certa percepção (a nutrição, no caso de nosso exemplo) cuja imagem mnêmica permanece, daí em diante, associada ao traço que deixou na memória a excitação produzida pela necessidade. Na próxima vez que esta última sobrevenha, devido ao enlace assim estabelecido, suscitará uma moção psíquica que quererá investir novamente a imagem mnêmica daquela percepção e produzir outra vez a percepção mesma, vale dizer, na verdade, restabelecer a situação da satisfação primeira. Uma moção dessa índole é o que chamamos desejo, a reaparição da percepção é o cumprimento do desejo, e o caminho mais curto para este é o que leva desde a excitação produzida pela necessidade até o investimento pleno na percepção (Freud, 2006a, pp. 557-558).

O que é reativado diante da necessidade é apenas a lembrança, a marca mnêmica da vivência de satisfação, por meio do pensamento alucinatório. Assim, essa reativação não acompanha o objeto real, mas fantasiado, sendo o desejo ligado a traços mnêmicos, buscando sua realização na reprodução alucinatória das percepções, que se tornaram sinais dessa satisfação.

A alucinação entra no lugar do objeto real porque a vivência de satisfação plena pode ser considerada, por si só, uma ilusão. Assim, o objeto dessa satisfação estará para sempre perdido, dada à impossibilidade de satisfação plena. O desejo nasce na falta, é por causa da experiência de falta, de insatisfação e de frustração que o desejo se faz presente. Move-se o psiquismo. Inaugura-se o sujeito: "Todo sujeito é sujeito de um desejo, ou melhor, todo sujeito é sujeito porque é desejante" (Kehl, 1990, p. 368).

No texto "Mal-estar na civilização" , Freud (2006e) se refere a uma das características fundamentais na natureza do homem, decisiva na articulação com o desejo. 0 desejo e, portanto, sua tentativa de se satisfazer, é regido totalmente pelo princípio do prazer. No entanto, o próprio princípio do prazer é contraditório: a busca da felicidade é a busca da experiência de uma satisfação intensa, e ao mesmo tempo, de uma 
satisfação constante, ou seja, a felicidade é almejada como algo intenso e, ao mesmo tempo, que dure para sempre: ambos propósitos do princípio do prazer.

Assim, esse princípio é paradoxal: ele exige o prazer, mas se a busca pela satisfação plena for levada até o limite, encontra-se o desprazer. Se o eu realizar todos os desejos de forma irrestrita, os danos a si e ao outro são inevitáveis. Daí o valor do recalque. Em última análise, o que se recalca é o desejo de plenitude. Recalca-se o desejo, mas ele não morre. Ele continua buscando satisfação em seus substitutos, como ressalta Sanches (2010, p. 98):

Nesse sentido, a grande força motriz da ação de um sujeito, em Freud, é a busca de retorno a esse momento de satisfação plena, que nunca mais será revivido integralmente, como também é essa busca do substrato para toda a construção do aparelho psíquico, além da fonte de sua energia.

E é nessa busca que é possível articular a escuta da expectativa em relação ao atendimento psicológico, com a escuta parcial do desejo na sua concepção psicanalítica. Parcial porque, o desejo, dado à força do recalque, não se manifesta integralmente. 0 recalque tem também a função de proteção do eu. Assim, embora em uma entrevista de triagem psicológica de orientação psicanalítica se possa reconhecer parte do desejo na elaboração das expectativas, vale a regra de ouro acerca da verdade do psicanalista e do paciente:

Nisso tudo, porém, nunca deixamos de fazer uma distinção rigorosa entre o nosso conhecimento (psicanalista) e o conhecimento dele (paciente). Evitamos dizer-Ihe imediatamente coisas que muitas vezes descobrimos num primeiro estágio, e evitamos dizer-lhe a totalidade de que achamos que descobrimos. Refletimos cuidadosamente a respeito de quando Ihe comunicamos o conhecimento de uma de nossas construções e esperamos pelo que nos pareça ser o momento apropriado... Via de regra, adiamos falar-lhe de uma construção ou explicação até que ele próprio tenha chegado tão perto dela que só reste um passo a ser dado... Se procedermos doutra maneira e o esmagamos com nossas interpretações antes que esteja preparado para elas, nossa informação ou não produziria efeito algum ou, então, provocaria uma violenta irrupção da resistência que tornaria o avanço de nosso trabalho mais difícil ou poderia mesmo ameaçar interrompê-lo por completo (Freud, 2006f, p. 205).

Mannoni (2004), sobre a primeira entrevista em psicanálise, momento em que a triagem psicológica psicanalítica se insere, refere que é a presença do psicanalista que vai ajudar o sujeito a articular sua demanda, constituir-se na sua fala em relação à sua história, a fim de extrair uma mensagem em que poderá ser veiculado um sentido. Porém, sentido não é sinônimo de desejo. O sentido pode ser verbalizado e interpretado, mas, e o desejo?

Freud (2006c), no texto "Sobre o início de tratamento", alerta que não é difícil para um analista treinado identificar os desejos inconscientes do paciente nas entrelinhas de suas queixas e de sua doença, e que seria vaidade e falta de reflexão comunicá-los ao paciente antes que ele próprio tivesse algum conhecimento sobre si mesmo. 
A que serve então, ao psicanalista, o acesso ao desejo inconsciente se o paciente se encontra distante de sua própria verdade? Freud responde a essa questão afirmando que a força motivadora inicial do tratamento não é suficiente mantê-lo, colocando-se assim duas dificuldades: não se sabe que caminhos seguir para livrar-se de seu sofrimento e não possui necessária cota de energia para se opor às resistências. É em relação à primeira dificuldade que o fato de o analista conhecer o desejo inconsciente pode ajudar. No percurso do caminho que levará o paciente a se aproximar de si mesmo, de seu desejo.

\section{Objetivo}

A partir da apresentação da história clínica, história de vida do participante e das expectativas em relação ao tratamento psicológico verbalizadas na entrevista de triagem, objetivou-se extrair uma compreensão e uma articulação entre expectativas acerca do atendimento psicológico e o desejo inconsciente inerente às expectativas.

\section{Método}

Este artigo é fruto de uma pesquisa de mestrado apresentada no Instituto de Psicologia da Universidade de São Paulo. O método utilizado foi clínico qualitativo.

\section{Participantes}

Foram entrevistados dez participantes maiores de 18 anos, sendo um do sexo masculino e nove do sexo feminino, inscritos no Serviço-Escola de uma universidade do interior de São Paulo. A relação entre expectativa e desejo será feita a partir de vinhetas clínicas de um desses casos.

\section{Critério de inclusão}

O participante não ter tido experiência em psicoterapia individual, a fim de que as expectativas referidas não estivessem atravessadas pela experiência de fato.

\section{Instrumentos}

Entrevista de triagem psicológica semiestruturada.

\section{Procedimentos}

A partir de uma análise criteriosa dos dez casos apresentados na dissertação, um foi selecionado para articular expectativas e desejo, pela aparente clareza em que essa relação se destacou no discurso do entrevistado. As entrevistas foram agendadas pelo serviço por telefone a partir de inscrição prévia dos interessados no atendimento psicológico. Foram realizados dois encontros em cada caso para melhor compreensão da demanda. Por motivos de ordem ética e com o objetivo de preservar sigilo e a confiden- 
cialidade dos dados do participante, o nome é fictício e serão utilizados apenas recortes das entrevistas de triagem, seguidos da análise a partir da perspectiva psicanalítica.

\section{Cuidados Éticos}

Os participantes assinaram o TCLE autorizando a utilização dos dados para publicação. A pesquisa foi aprovada pelo comitê de Ética em 12.5.2011, Protocolo n. 073/11 CEP/ICS/Unip.

\section{Caso - João}

João tem entre 50 e 59 anos. Procurou atendimento psicológico espontaneamente. Faz acompanhamento psiquiátrico e o psiquiatra o diagnosticou com depressão, prescrevendo antidepressivo. Descreve apatia, falta de vontade para realizar atividades da vida cotidiana como trabalhar e comer e dorme muito. Refere que vive só, não tem vínculos sociais e nunca se relacionou amorosamente.

Quando criança, morava com irmãos e pais em uma área rural. Os irmãos mais veIhos se casaram e a família se mudou para a cidade. Os pais se separaram quando ele ainda era criança. Ele ficou com o pai e o irmão mais jovem com a mãe; por opção da mãe, segundo o relato. Essa divisão foi vivida por ele como uma rejeição. Relata que não tinha com o pai a mesma afinidade que tinha com a mãe. Era apegado a ela. Não entendia por que ela escolhera o irmão e não a ele. Ele disse na entrevista: "Minha mãe olhou muito mais para o meu irmão do que para mim, a vida toda".

O pai faleceu e ele voltou a morar com a mãe já adulto. Ele sentia uma grande distância dela em relação a ele. "Meu irmão tinha, até ela morrer, toda a atenção dela." Após a morte da mãe, João, que já apresentava um quadro de depressão, desenvolveu sintomas compatíveis com a síndrome do pânico. Taquicardia, sudorese, medo de sair de casa, dores abdominais, diarreia. Após consulta com psiquiatra, ele foi afastado do trabalho e encaminhado para psicoterapia e iniciou um processo em grupo no sistema público de saúde de seu município. Ao mesmo tempo, se inscreveu no serviço de psicologia da universidade ficando em lista de espera alguns meses.

Na entrevista de triagem do Serviço-Escola, ao ser perguntado sobre o que esperava do atendimento psicológico, ele respondeu: "de verdade, eu queria atendimento individual. Não quero mais fazer terapia em grupo". Ele diz isso de cabeça baixa, mas olhando no rosto do entrevistador, como quem aguarda um assentimento. Estimulado a falar mais sobre esse desejo, ele explica.

No atendimento em grupo, a profissional tem que dividir sua atenção com todo mundo que está ali. Ela não consegue dar uma atenção individual. Eu acho que ela me ouve pouco e quase não olha para mim e para meu sofrimento. Eu preciso de alguém que me escute de verdade, que me olhe e só de olhar já saiba o que eu estou sentindo naquele dia e me diga o que eu sinto, porque eu mesmo muitas vezes não sei dizer, entender. Vocês são treinados para isso, né? Que me dê atenção integral. O trabaIho em grupo não está ajudando, às vezes me sinto pior lá. 
O entrevistador questiona: "Como se sente quando está lá?". Ele responde: "Tenho muita raiva, mas muita mesmo... Acho que a psicóloga não acha interessante o meu caso. Mas não devia ser assim. Ela deveria olhar igual para todo mundo. Todos que estão lá sofrem, não tem sofrimento maior ou menor, não é?".

É interessante observar como a percepção que João tem do trabalho em grupo, suas queixas, os sentimentos de raiva e exclusão por ele relatados, se articulam com a queixa latente ("minha mãe não olhava para mim") e com seu desejo de ser único e de ser olhado. A questão do olhar se repete em sua fala. Mas que olhar é esse que João deseja?

João parece reproduzir em sua fala um conflito infantil vivido na relação com a mãe que, segundo o relato de sua história de vida, faz uma escolha pelo seu irmão: "Minha mãe olhou muito mais para o meu irmão do que para mim, a vida toda." João, ao se referir ao trabalho de terapia em grupo, revela: "No atendimento em grupo, a profissional tem que dividir sua atenção com todo mundo que está ali. Ela não consegue dar uma atenção individual. Eu acho que ela me ouve pouco e quase não olha para mim e para meu sofrimento". Na transferência, João deseja ser único. E deseja ser compreendido como um bebê que é satisfeito, sem que precise enunciar. Ele pede: "Eu preciso de alguém que me escute de verdade, que me olhe e só de olhar já saiba o que eu estou sentindo naquele dia e me diga o que eu sinto, porque eu mesmo não sei. Vocês são treinados para isso, né?"

Onde ainda não há linguagem verbal, é o corpo quem fala. Um corpo que primordialmente é investido pela mãe que, ao exercer suas funções, ao cuidar de seu bebê, erotiza seu corpo. E erotiza justamente pelo fato do bebê não ser apenas um pedaço de carne, mas sim um corpo simbólico, investido pelo outro de afeto e de palavras (Zornig, 2008).

Obviamente, o psicanalista não é testemunha ocular de como se constituiu um paciente nas suas relações primitivas, mas é ali, onde se inscreve a transferência e suas manifestações, que é possível acessar aspectos primitivos da constituição do sujeito.

Esse pedido de João na primeira entrevista com o psicanalista, revela transferencialmente seu desejo: "Olhe para mim, e diga quem sou". O olhar narcísico, especular, que idealiza o outro e o coloca em um lugar de onipotência.

João, ao criticar o atendimento em grupo como um lugar onde ele não consegue existir, ao esperar uma terapeuta que o atenda individualmente para que possa ser visto e ouvido em sua singularidade, que saiba sobre ele mais do que ele próprio, deseja o olhar de alguém que diga quem ele é. Vivência do narcisismo primário, em que o ego se constituiria como unidade psíquica em um correlato com a constituição do esquema corporal, "no qual uma unidade é precipitada por uma determinada imagem que o sujeito adquire de si mesmo segundo o modelo do outro, que é precisamente o ego" (Laplanche \& Pontalis, 2001, p. 288).

João menciona que não tem amigos e que nunca se relacionou amorosamente. Atualmente, vive em função de seu sofrimento. Pelo princípio de conservação da ener- 
gia libidinal, reinveste o ego desinvestindo os objetos, e quanto mais o eu absorve, mais os investimentos nos objetos se empobrecem (Freud, 2006d).

A partir da queixa de depressão e síndrome do pânico, considerando que esses quadros apontam para a angústia do inominável e do indizível e articulando suas expectativas em relação ao atendimento psicológico, pode-se supor que João deseja uma relação em que o outro organize seu caos, a partir de uma ação específica vinda de um outro. É em uma comunicação transferencial que João formula sua expectativa, e ao fazê-la, revela o desejo infantil, primitivo de ser único e um com o outro.

Escutar o desejo tem assim o valor de uma comunicação, de um entendimento que pode gerar uma ação específica por parte do psicanalista. Não a ação de satisfação do desejo, impossível de ser realizado, mas sim de uma satisfação parcial. Ao favorecer um atendimento individual, algo do desejo de ser único se realiza, abrindo um campo transferencial onde o trabalho psicanalítico possa acontecer.

\section{Conclusão}

Por meio de uma entrevista de triagem psicológica em que uma das perguntas disparadoras era sobre expectativas acerca do atendimento psicológico e baseando-se em uma análise psicanalítica que leve em conta a escuta das manifestações inconscientes, coletou-se elementos importantes que possibilitaram uma compreensão do desejo que, na concepção freudiana, é motivo e motor do psiquismo.

Perguntar sobre as expectativas permite que algo desse desejo seja acionado e trazido para a relação transferencial.

O resultado obtido no caso apresentado revela que, desde o início do tratamento psicanalítico, uma escuta atenta ao que o paciente espera do atendimento e não só o que o profissional tem a oferecer, pode favorecer que aspectos primitivos sejam reeditados na cena transferencial e que, a partir dessa compreensão, as peças do quebra-cabeça comecem a ser conhecidas pela dupla psicólogo-paciente.

A análise do caso apresentado revela que as expectativas apresentadas por João se articulam com conflitos primários que ele verbalizou na triagem: sentimentos de rejeição, desejo de ser visto, de ser único e de ser um com o outro, idealização do profissional investindo-o de onipotência, revelando uma demanda de amor infantil.

Assim, é possível verificar a preciosidade da escuta das expectativas do paciente, momento para a compreensão de sua dinâmica psíquica e do desejo inconsciente inerente às expectativas acerca do atendimento psicológico. 


\section{Referências}

Alves, R. (2004). Escutatória. In Alves, R. O amor que ascende a lua. (pp. 65-71). Campinas: Papirus.

Cerioni, R. A. N. (2014). Expectativas de pacientes acerca do atendimento psicológico em uma clínica-escola: da escuta à adesão (Dissertação de Mestrado). Universidade de São Paulo, São Paulo, SP, Brasil.

Freud, S. (2006a). A interpretação dos sonhos. In Freud, S. Edição standard das obras psicológicas completas de Sigmund Freud (Vol. IV e V, pp. 39-649) (J. Salomão, Trad.). Rio de Janeiro: Imago.

Freud, S. (2006b). A dinâmica da transferência. In Freud, S. Edição standard brasileira das obras psicológicas completas de Sigmund Freud (Vol. XII, pp. 109-119) (J. Salomão, Trad.). Rio de Janeiro: Imago.

Freud, S. (2006c). Sobre o início do tratamento. In Freud, S. Edição standard brasileira das obras psicológicas completas de Sigmund Freud (Vol. XII, pp. 163-187) (J. Salomão, Trad.). Rio de Janeiro: Imago.

Freud, S. (2006d). Sobre o narcisismo: Uma Introdução. In Edição standard brasileira das obras psicológicas completas de Sigmund Freud (Vol. XIV, pp. 77-108) (J. Salomão, Trad.). Rio de Janeiro: Imago.

Freud, S. (2006e). O mal-estar na civilização. In Edição standard das obras psicológicas completas de Sigmund Freud (Vol. XXI) (J. Salomão, Trad.). Rio de Janeiro: Imago.

Freud, S. (2006f). A técnica da Psicanálise. In Edição standard das obras psicológicas completas de Sigmund Freud (Vol. XXIII, p. 205) (J. Salomão, Trad.). Rio de Janeiro: Imago. (Obra original publicada em 1938).

Gay, P. (2004). Freud: Uma vida para o nosso tempo (D. Bottmantrad, Trad.). São Paulo: Ed. Schwarcz.

Gobbi, A. S. (2008). O narcisismo na clínica contemporânea. Contemporânea, Psicanálise e Transdisciplinaridade, 6(1), 24-35. Disponível em: http://www.revistacontemporanea.org.br/site/wp-content/artigos/artigo186.pdf.

Herzberg, E., \& Chammas D. (2009). Triagem estendida: serviço oferecido por uma clínica-escola de Psicologia. Paideia, 19(42), 107-114. DOI: 10.1590/S0103$-863 \times 2009000100013$.

Kehl, M. R. (1990). Desejo de realidade. In A. Novaes, A. (Org.). O desejo (pp. 363382). São Paulo: Companhia das Letras.

Laplanche J., \& Pontalis, J.-B. (2001). Vocabulário da Psicanálise. São Paulo: Martins Fontes. 
Macedo, M. M. K., \& Carrasco L. K. (2005). A entrevista clínica: um espaço de intersubjetividade. In (Con)textos de entrevistas: olhares diversos sobre a interação humana (p. 26). São Paulo: Casa do Psicólogo.

Macedo, M. M. K., \& Falcão C. N. B. (2005). A escuta na psicanálise e a psicanálise da escuta. Psyche., 9(15), 65-76. Disponível em: http://pepsic.bvsalud.org/scielo. php?script=sci_arttext\&pid=S1415-11382005000100006\&lng=pt\&tIng=pt.

Manoni, M. (2004). A primeira entrevista em psicanálise. Rio de Janeiro: Elsevier.

Perfeito, H. C. C. S., \& Melo, S. A. de (2004). Evolução do processo de triagem psicológica em uma clínica-escola. Estudos de Psicologia, 21(1), 33-42. DOI: 10.1590/ S0103-166X2004000100003.

Rocha, M. C. (2011). Plantão psicológico e triagem: aproximações e distanciamentos. Revista do NUFEN, 3(1), 119-134. Disponível em: http://pepsic.bvsalud.org/ scielo.php?script=sci_arttext\&pid=\$2175-25912011000100007\&lng=pt\&tlng=pt.

Sanches, P. R. P. (2010). A alteridade na conceituação freudiana de desejo e pulsão. Revista Brasileira de Psicanálise, 44(4), 97-108. Disponível em: http://pepsic. bvsalud.org/scielo.php?script=sci_arttext\&pid=S0486-641X2010000400009\&lng= pt\&tlng=pt.

Zornig, S. M. A-J. (2008). As teorias sexuais infantis na atualidade. Psicologia em Estudo, 13(1), 73-77. DOI: 10.1590/S1413-73722008000100009.

Submissão: 27.11.2015

Aceitação: 14.9.2016 